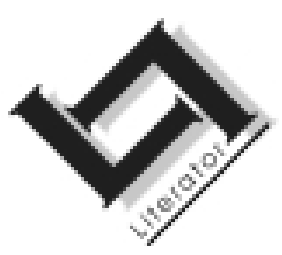

\title{
The man with the phrase book in his head: On the literariness of the illiterate Homer
}

\author{
Jaco Alant \\ School of Literature \& Language Studies \\ University of the Witwatersrand \\ JOHANNESBURG \\ E-mail: bualant@iafrica.com
}

\begin{abstract}
The man with the phrase book in his head: On the literariness of the illiterate Homer
\end{abstract}

In the early 1930s Milman Parry's theoretical substantiation of the oral composition of the Iliad and the Odyssey was widely interpreted as a major breakthrough in the field of oral traditional research, even as the founding act of a new discipline - Oral Theory. The "oral-formulaic" theory which underscored this breakthrough has, however, been increasingly criticized in recent times. While acknowledging the fundamental importance of Parry's work in the field of Oral Theory, the present article seeks to reinterpret the essential orality of the Homeric poems in the light of its broader implications for the recognition of an oral aesthetics/oral literature. Parry's work on the Iliad and Odyssey has generally been appreciated for its postulation of a characteristically oral textual economy. This article sets out, by contrast, to look more closely at the possibility Parry opens up for the orally composed text to be considered "literature" in its fullest aesthetic sense. Crucial to this is the creative role of the reader/audience in terms of the text's "horizons of expectations", that also serve to contradict the famous characterisation by Walter Ong alluded to in the title of this article.

\section{Introduction}

Ong's tongue-in-cheek characterisation of Homer as the man with "some kind of phrase book in his head" (Ong, 1982:18) invites us to confront our generally comfortable preconceptions regarding so-called "great" (or "timeless") art and literature. This article will in no way contradict the notion that the Homeric poems are indeed great literature, yet it will not take particular umbrage at Ong's rather reductive view of (the great) Homer either. In seeking what exactly it is in the Iliad and Odyssey that 
makes these poems so "prestigious", so "literary", we will come to the conclusion that the supposed "genius" (or, for that matter, phrase book!) of their presumed author is really of no consequence. The key element in the greatness of the Iliad and Odyssey is their reception. This is true not only of the Iliad and Odyssey, but in fact, of all "literature". Could this also be true of oral literature? And of what significance then is the orality (the presumed fact that they were not composed in writing) of the Homeric poems? In order to answer these questions, we need to begin with the theory that has irrevocably linked the Iliad and Odyssey to oral tradition: the oral-formulaic theory.

\subsection{The oral-formulaic theory: background and criticism}

In the early 1930s Milman Parry's research on the structure of the hexameter verse of the Iliad and the Odyssey convincingly concluded that the poems were orally composed. Working in conjunction with Albert Lord, who was to carry on his work after his death, Parry found comparative verification for the theory behind his findings in a subsequent study of the oral poetry of the guslari of Serbo-Croatia. Popularized in Lord's immensely influential The Singer of Tales, the oralformulaic theory is also frequently referred to as the Parry-Lord thesis.

At the top end of the scale John Miles Foley $(1986,1988)$ and Walter Ong $(1982,1987)$ have lauded Parry and Lord as providing the theoretical framework for nothing less than a new (albeit strongly interdisciplinary) field called - among others - "Oral Theory" (Foley) and "Orality-Literacy Studies" (Ong). Other appraisals have been less enthusiastic, or at least more careful. At the core of the divergent appraisals of Parry and Lord's work lies the vexed issue of the originality of the oral. On the one hand, every commentator of oral tradition is in agreement as to the need for the oral text ${ }^{1}$ to be studied, appreciated and interpreted "on its own terms", and it is on this basis that the notion of a "great divide" between literacy and orality has to some extent been justified - at least as a starting point - as a model for studies in oral tradition (Foley, 1994:169). On the other hand, this generally welcome development has had uncomfortable by-products. Cautioning against an over-zealous application of the oral-formulaic theory's "more ambitious claims" (Finnegan, 1977:72), Ruth Finnegan offers observations from a wide range of oral traditions that serve to contradict the basic tenets of

1 "(A) real, objective and tangible score, an entity that exists both as a thing in itself and as a directive for its perceivers" (Foley, 1990:5). "Text" in this sense includes "performance". 
the theory2 (Finnegan, 1977:69-87). Furthermore, the literacy vs orality model, with its emphasis on the differences between written and oral textuality, has tended to obscure what more recently has become an important area of research in its own right, namely the issue of the "overlapping" of the literate and the oral. Werner Kelber, for one, has warned against the tendency - promoted by the oral-formulaic theory to see in the (supposed) fact that "the Homeric poems were composed without the aid of writing" some kind of "essentialist (oral) purity" (Kelber, 1994:199).

The type of criticism of the Parry-Lord thesis voiced here by Finnegan and Kelber can be regarded as theoretical (or scholarly) in the ordinary sense - a theory is evaluated and critiqued for its import to a specific field of study. With Leroy Vail and Landeg White, however, this criticism becomes distinctly ideological. According to them, the oral-formulaic theory offers the proverbial (theoretical) backdoor for nothing less than racism. A "psychologizing interpretation" of the notion of the formula (in which they see Ong as one of the main culprits) has led to the racist elaboration of "oral man" (see Vail \& White, 1991:1-39). No longer is the question of literacy/orality merely a theory to be supported, modified or set aside according to the evidence of a field of scholarship. Just as in dichotomies like "civilised vs savage" and "scientific vs primitive", the difference implied by orality takes on the entire political burden of the historical discrimination against people on the basis of predefined categories.

Ong shows an awareness of the ideological dimension of orality when he describes the usefulness of the Parry-Lord thesis for addressing the Homeric poetry "on this poetry's own terms" as an "undercutting ... (of) chauvinism" (Ong, 1982:18. My italics). In a way then, Ong can be said to present the Parry-Lord thesis at the kind of ideological level at which detractors like Vail and White pitch the essence of their criticism. Ong's awareness of the implications of the Parry-Lord thesis for questions of social power and prestige are important - there is, of course, a similar awareness in the remark by Ong from which I derive the title of this article.

There is one more point of criticism of the oral-formulaic theory that is of importance to us. White (1989:34) takes issue with Parry and Lord's

2 Finnegan's critique centres in the following questions: To what extent is an oralformulaic style indeed indicative of oral composition? Can the formula be defined with enough rigour for it to constitute a distinctive feature of the oral text? Must the text of necessity be composed in performance? 
overarching concern with oral textuality or form, and accuses them of "(breaking) the link between performance and history". On a theoretical level this criticism, stressing the need for an interpretation of the oral text "beyond the confines of its textuality" (Barber \& De Moraes Farias, 1989: 3 ), has given impetus to the so-called "performance-centred" approach in oral tradition.

What we are left with is an impasse between structure on the one hand the oral-formulaic theory - and, on the other, "the processes of performance and audience reception as they actually take place in space and time" (Finnegan, 1986:74) - the performance-centred approach. But as Foley (1992:280) reminds us, Parry's original research was first and foremost concerned with proving the traditional character of the Homeric poems. That the peculiar structures indicative of tradition implied orality was only a subsequent revelation (see Parry, 1971:439). Surely, if the oral formulaic theory's indebtedness to tradition is taken seriously, it should no longer be seen as exclusive of meaning? There is, moreover, no reason why tradition cannot indicate extratextuality. "What if it [tradition] came to refer to a reality larger even than the entire individual performance, or group of performances?" asks Foley (1992:281).

Clearly, the performance-centred approach needs to look no further than tradition for the meaning it aspires to. Both the Parry-Lord thesis and the performance-centred approach lay claim to verbal art as "a situated, experienced event in traditional context" (Foley, 1992:277). On this basis Foley is able to proceed to an integration of the two positions around the seductive matrix: "performance [text] ${ }^{3}$ as the enabling event and tradition as the enabling referent" (Foley, 1992:294).

\subsection{From the traditional to the literary}

Performance is an enabling event (or sign, signifier?), tradition is an enabling referent (or meaning, signified?). Foley's proposed method will, in fact, be one way of reconceptualising the significance of Homer's orality as creative of literature. Reconnected with meaning (which is embedded in the tradition he is actualising), the virtuoso technician can fully claim to be a poet. In this article I am suggesting another way. Where Foley departs from the notion of tradition, I am taking as point of departure the notion of literature. Where Foley reminds us of the importance of Parry's original conception of the traditional in order to albeit in reduced fashion, also be applicable to the "oral-derived" text. 
establish (a framework for) meaning, I wish to reflect more particularly on the implications of Parry's breakthrough concerning the orality of the Iliad and the Odyssey for what we regard as literature.

Literature, of course, implies meaning. But the issue of the "meaning of oral texts" (imaginatively addressed by many commentators) is not really my concern here. My preoccupation is more specifically with literature as a specific type of discourse to which a certain prestige and consequently a degree of political power are attached. Beyond questions of textuality and meaning, important as they are, what is obviously crucial in this context is the issue of audience/reader reception. I shall therefore make strong reference to what is known in the English-speaking world as reader-response theory, more particulary to Hans Robert Jauss's concept of "horizons of expectations". The reception of Homer's Iliad and Odyssey will be central to my argument. As I hope to indicate, their reception as literature should at least raise possibilities of literariness and prestige - for oral texts from a variety of traditions.

\section{What is "art" in oral art, or "literature" in oral literature?}

\subsection{Literature as prestige/influence}

It should be clear from the preceding that, for purposes of this article, I am setting aside the post-modernist/deconstructionist argument which seeks to refute the distinction between "high" and "popular" culture hence between the literary and the non-literary - through its assignment of all aesthetic discourse to the all-encompassing sea of (inter) textuality (Easthope, 1990). Literature is at the very least something relatively specific. As Tony Bennett (1990:273) puts it:

... whilst its [the concept of literature's] conventional understanding as a uniquely privileged kind of writing cannot be sustained, the term does cogently designate a specific, but non-unitary, field of institutionally organised practices - of writing, reading, commentary and pedagogy.

The oral literary text is therefore by extension regarded as at least in principle distinguishable from the oral text as such. It is also in this sense that I take the concept of oral art (aesthetic) to be relatively distinct from the concept of oral culture. Not all culture is necessarily artistic.

The most obvious category of literature in this sense is what is frequently referred to as the "canonical": texts that over periods of prescribed institutionalised study and critical attention acquire the kind of prestige that makes them "classics". Canonical literature has been characterised in various ways, most often in relation to its supposed ability to retain interest and relevance over extended periods of time: " $(T)$ he work is 
assumed to transcend history because it encompasses the totality of its tensions within itself", comments Paul de Man (in Jauss, 1982:xi). A different type of characterisation, within the context of what is considered a "high" literary work, is given by Anthony Easthope (1990:90). In relation to the popular, the literary work has a relative plurality of meaning; its meaning is "deferred", the text means "more than it says".

In developing his aesthetic of reception, Jauss is critical of "essentialist" conceptions in terms of which the meaning of a work is characterised as "representational or expressive function" (Jauss, 1982:15). He is equally critical of Hans-Georg Gadamer's idea (already expressed in De Man's observation above) that the classical text "signifies itself and interprets itself" (Gadamer, in Jauss, 1982:30). In Gadamer's view the classical work, addressing itself to a kind of eternal present - a "timeless ideality" (Jauss, 1982:13) - achieves its own historical mediation without the interference of a reader/audience. Yet to Jauss the true meaning ("historical essence") of a work lies strictly speaking outside the work - in its influence. "The work [of literature] lives to the extent that it has influence. Included within the influence of a work is that which is accomplished in the consumption of a work as well as in the work itself" (Karl Kosík, in Jauss, 1982:15; my italics). "Influence" in this sense involves a multifaceted dialectic of author, work and public, in which "the perpetual inversion occurs from simple reception to critical understanding, from passive to active reception, from recognized aesthetic norms to a new production that surpasses them" (Jauss, 1982:19). If the key concept in all of this can be traced to the idea of productivity of meaning, it is the reader - the addressee (who includes both the critic and the reflective consciousness of the author) - that takes on the prime role in its development. And the basis for this productivity is the reader's horizon of expectations, which

describe the criteria readers use to judge literary texts in any given period. These criteria will help the reader decide how to judge a poem as for example an epic, or a tragedy or a pastoral; it will also, in a more general way, cover what is to be regarded as poetic or literary as opposed to unpoetic or non-literary uses of languages 4 (Selden, 1985:14).

4 "The horizon of expectations of literature ... not only preserves actual experiences, but also anticipates unrealized possibility, broadens the limited space of social behavior for new desires, claims, and goals, and thereby opens up paths of future experience" (Jauss, 1982:25). 
Jauss's aesthetic of reception generally situates the greatness of the classic work in the addressee's reaction to it. What causes a work of literature to be a classic, a "masterwork"? At issue is the degree to which a work demands of its addressee a change towards as yet "unknown experience". This crucial change is the "aesthetic distance" the addressee is required to cover between his own horizon of expectations (which involves his "familiarity of previous aesthetic experience") and that required for the reception of the work. Moreover, this change reveals itself, at least at first, as negativity. The masterwork is distinguished from "entertainment art" (the popular?) to the extent that this aesthetic distance is relatively great. By contrast, in the latter (also called "culinary" art), the reception of the work requires little or no change on the part of the addressee, and blithely fulfils expectations, satisfies desires, "solves" problems (Jauss, 1982:25) 5 .

Our brief incursion into the workings of the canonical can be justified, of course, by the enormous prestige enjoyed by the Homeric poems. The following description is by no means uncommon: "The lliad is the first substantial work of European literature, and has fair claim to be the greatest ... (I)t may fairly be described as the cornerstone of Western civilisation" (Hammond, 1987:7). This virtually universal prestige of the Iliad and the Odyssey is, of course, in stark contrast to the still prevailing dismissiveness - at least at the level of genuine aesthetic appreciation which characterises the reception of oral texts generally. The crux of the matter is that the oral text, though quite commonly called "literature", has tended, by and large, to be merely "collected" as "evidence" of a particular type of culture. This point is well made by Karin Barber. Reflecting specifically on African oral literature, she decries the lack of any "developed criticism" in regard to the latter, as a result of which "scholars [who have trained in the tradition of 'mainstream criticism'] ... have tended to abandon the attempt to criticise oral literature and have fallen back instead on the mere collection and annotation of texts". The reason for this, she advances, "is to be found in the political situation of oral literature in general ... Oral literature everywhere has been or is being marginalized with the displacement and impoverishment of its bearers, the illiterate peasantry" (Barber, 1984:497).

5 It is an interesting feature of the aesthetics of reception that the initial aesthetic distance covered by the readers of a work "can disappear for later readers, to the extent that the original negativity of the work has become self-evident and has itself entered into the horizon of future aesthetic experience, as a henceforth familiar expectation". This, according to Jauss, may bring the classic work close to being mere entertainment ("culinary art"), requiring "a special effort to read ... [it] 'against the grain' of the accustomed experience" (Jauss, 1982:25-26). 
A further point can be made here, concerning the prestige accorded to particular oral texts within the community in which they have been produced. On one level it should be obvious that, within a given culture, some texts (for example praise poems) should be considered as more expressive of power, more "serious" than others (riddles, for example). Yet such distinctions are frequently ignored by a scholarly treatment intent on seeing oral texts as "ethnographic documents". While oral societies are commonly said to have "literature" by analogy with literate societies - "just like us" - oral texts are generally only differentiated within a functionalist perspective, with comparatively little attention given to questions of status or prestige. This attitude can at least partly be attributed to two inter-related notions: the notion that oral societies tend towards "cultural homeostasis" (Goody, 1977:14) and the more Romantic notion of oral societies being "egalitarian" (Finnegan, 1977:34). Slowness of change and perpetual equality do not really promote a perspective on texts as indicative of social power. Yet, as Barber and De Moraes Farias (1989:2) argue, the idea of a "society" or "people" having a "monolithic and homogeneous culture, equally shared by all its members" no longer holds. Many societies are, in fact, characterised by "extraordinarily complex internal cultural differentiation", making it impossible to assign "a single determinate 'translation' to any ideological phenomenon in any society". I see this as implying a generally more "conflictual" model for the oral culture, with that culture's texts being subject to horizons of expectations variously addressing issues of power, tension and conflict. This is a manifestly different perspective to the one that has generally been put forward regarding the oral text in relation to conflict, namely that the text (most famously the folktale) addresses potential conflict, exerting "a stabilizing influence" through its fulfilment of some predetermined societal (pedagogical) function.

Of course, the audience of an oral performance participates in its creation and in its production of meaning in ways unthinkable for the reader of the written text (Finnegan, 1977:122). But in the final analysis the kind of explanation Jauss provides for the most influential kind of literature does not really apply to the oral. Not, I would hold, because oral societies somehow lack the conception or possibility of "aesthetic distance" (there is ample evidence to the contrary), but simply because research into oral tradition has failed to develop its own horizon of expectation with regard to the oral text. The following observation by Olabiyi Yai (1989:59) still holds true:

No communication seems to exist between the production/ consumption of oral poetry and its criticism. More precisely, communication is unidimensional. When the creator of oral poetry and his academic critics are contemporaries the terms of the critical 
exchange are unilaterally set by the critic. The poet is thus degraded from his status of creator to that of an informant. He can only make such contributions as required by the initiatives of the critic.

We need not give up here, fortunately, for we still possess the example of those ultimately prestigious oral texts, the Iliad and Odyssey. The degree to which their reception counters the diminution of the ultimate poet to the "man with the phrase book in his head" may yet yield possibilities for the recognition of a genuine oral literature.

\subsection{Literature as creativity}

In the article already referred to, Foley (1992:275) draws attention to "customary organizing principles" which "delineate" the texts of oral cultures. Of these he mentions "author" ("artist"), "text", "genre" and "tradition" (given this article's interest in reception aesthetics, let us also add "addressee" or "audience"). As discussed in the introduction, Foley embarks on a kind of theoretical merger of the notions of text (as performance) and tradition: performance as enabling event, tradition as enabling referent. But the "grid" he provides us with is particularly useful for another reason. It defines conceptually separable categories (in the otherwise all-encompassing and amorphous "orality") against which and in which we can attempt our location of the crucial literary concept of creativity.

\subsubsection{Creativity as a quality of the artist}

Let us start with the artist, the poet - or the man with the phrase book in his head, provocatively characterised by Ong (1982:22):

Homer, by the consensus of centuries, was no beginner poet, nor was he a poor poet ... Yet it now began to appear that he had had some kind of phrase book in his head ... Homer stitched together prefabricated parts. Instead of a creator, you had an assembly-line worker.

Ong here catapults us headfirst into the major controversy of the ParryLord thesis, what Foley (1988:58) describes as "utility versus contextsensitivity ... convention versus originality". In fact, the man with the phrase book in his head represents the ultimate caricature of the oralformulaic theory. Faced with the overriding necessity to "keep going" (i.e. save face) in front of his all-too-easily distracted audience (the need for "compositional fluency"), Homer quite literally pulls out every trick in the bag, drawing on the "multiform" of expressions of the oral tradition. Rather than the literary ciriteria of "intellectual probing", "self-awareness" and "detachment" (Finnegan, 1973), his sole occupation is utility. 
Of course, there is (still) the more meliorative view of Homer, presented here by a recent translator of the Iliad, Martin Hammond (1987:11):

Homer was a poetic genius of quite exceptional power and range, who far excelled his predecessors (and his few successors) in technical skill, breadth of vision, quality of imagination, and sheer ambition.

Lest one is tempted to think that Hammond is somehow unaware of the oral traditional theory underpinning Homer's performance, this is decidedly not the case. He gives a succinct but precise account of the various multiforms (both prosodic and thematic) the oral poet employs, and is under no illusion as to the traditional elaboration of these forms: "The Homeric poems are in one sense the creation and final flowering of a long and distinguished tradition" (Hammond, 1987:11). Yet individual creativity has its definite - and decisive - place: "... (T)he pre-existing epic tradition was a necessary cause of the phenomenon of Homer, but not a sufficient cause" (Hammond, 1987:11; my italics).

In the passages quoted here, both Ong and Hammond, although they adopt virtually opposite standpoints, address the issue of the creativity of the oral at the level of the individual, the "author". Of course, the one advance of the Parry-Lord thesis that seems to be genuinely beyond dispute, is the fact that it liberated us (and well before post-modernism got around to it, we might add) from the hackneyed Romantic model of creativity: the solitary tortured poet pondering the Muse: creation ex nihilo (Ong, 1982:21-22). (This particular liberation coincides, of course, with Parry's ultimate demonstration, namely that the oral poet did not have to rely upon the obviously uncreative mechanism of rote memorisation.) The oral artist is not isolated; he is part of a society, a tradition, face to face with an audience. He does not create out of nothing, he improvises with the forms at his disposal. In the case of Homer, Hammond would no doubt say "improvises brilliantly" - he talks of Homer's "extraordinarily skilful control" (Hammond, 1987:14). As for the man with the phrase book in his head, Ong might well use the word "improvise" - he uses the word "rework" in a related context (Ong, 1982:23) - but then no doubt in the less flattering sense of "rehash with some alterations". In his assessment of the significance of a particular song undergoing changes in its transmission from one oral performer to the next, Lord, for his part, situates the creativity of the individual artist in the idea of the "preservation of tradition by the constant re-creation of it" (Lord, 1960:28). But, however tempting this type of characterisation (improvising, skillfully controlling, re-creating - and even conceding Hammond's point about tradition not being a sufficient cause for the phenomenon of Homer), we have to concede that the creativity of the 
individual remains submerged in the tradition of which it is the instrument - rather than the other way round. In Parry's own words: "there (are) ... certain established limits of form to which the play of genius must confine itself" (Parry, 1971:421).

\subsubsection{Creativity as a quality of the text}

The individual artist is, however, not only submerged in the tradition, he is equally submerged in the text. This is perhaps most obvious in the case of oral-derived texts 6 : "works of verbal art that took shape in or under the influence of oral tradition, but that now survive - for historical reasons - only as [written] texts" (Foley, 1992:290). The Iliad and the Odyssey being the definitive example of this type of (oral) text, let us remind ourselves that the very existence of Homer (quite apart from who he actually was) has over the years been a favourite subject of debate. But whereas in the case of the oral-derived text the individual artist is unknown to the point of simply being "not there", the oral performance shows perhaps a more theoretically compelling way of submerging the individuality of the artist. Of course, the oral artist is in all probability well known to the audience he performs to, perhaps even better known, in fact, than the author of a published book to its readers. In the case of the written text, however, the author's act of composition is clearly separate in time and space from its resultant object (the text) and can, for that reason, be studied in its own right. It is fashionable to ask authors questions about how they think about what they write. The same is not true of the oral text - at least the quintessential oral text, as intended by Parry and Lord - the text that is composed in performance. This text sees the conflation of the act of creation and the object of creation, of the composition of the text and the existence of the text. The entire process of creation (revolving, as composition of an individual text, around an individual artist) is "collapsed" into the text, disappears into it. Once composition has merged into text through the event of the performance, the text alone remains as instance of creativity.

An alternative way of describing the pre-eminence of oral creativity as being that of text rather than of artist can be formulated on the basis of Jean-Jacques Nattiez's (1990) model of the "symbolic phenomenon". The symbolic phenomenon (for our purposes, the text) is conceptualised as having three "dimensions", namely the poietic (relating to a process of

6 At a public lecture given by Foley in 1995, at the University of Natal, Durban, he in fact expressed doubts about the validity of this concept, in light of research that had brought to the fore oral texts - in the Parry-Lord sense of having been integrated into an oral tradition - deriving from texts originally composed in writing. 
creation that may be described or reconstituted), the esthesic (relating to the construction of meaning on the part of a receiver) and finally the trace or "neutral level" (relating to the physical and material embodiment of the symbolic form). Following our reasoning above, the oral text merges poietic (creative process) and trace (object of creation) into a single dimension alongside the esthesic, which is the appreciation of the oral performance by the audience.

\subsubsection{Creativity as a quality of the tradition}

We shall presently return to the question of the text as "instance" of creativity (within the grid of organising principles proposed by Foley). At this point, let us consider tradition. Perhaps an initial connection between tradition and creativity (which also relates to the artist) can be traced to Parry's idea of tradition enabling the artist, in Foley's words, to "(fill) his work with the spirit of a whole race" (Foley, 1988:21). Tradition makes it possible for the work of art to transcend the limits of the specific and aspire to the truly collective - to universality (which would naturally be a prime requirement for the timelessness of the classic we discussed earlier). Having developed this argument through an analogy with the "perfection" achieved by the Greek sculptor Phidias, Parry concludes:

We realize that the traditional, the formulaic quality of the diction was not a device for mere convenience, but the highest possible development of the hexameter medium to tell a race's heroic tales. The poetry was not one in which a poet must use his own words and try as best he might to use possibilities of metre. It was a poetry which for centuries had accumulated all such possibilities ... (Parry, 1971:425; my italics).

Directly addressing the notion of literariness in relation to tradition, Lord (1960:141) writes the following:

We realize ... [now] that what is called oral tradition is as intricate and meaningful an art form as its derivative 'literary tradition'. In the extended sense of the word, oral tradition is as 'literary' as literary tradition. It is not simply a less polished, more haphazard, or cruder second cousin twice removed, to literature. By the time the written techniques come onto the stage, the art forms have been long set and are already highly developed and ancient.

What enables Lord to conceive of tradition here as something "literary" in its own right stems in part, one feels, from a similar conception to that of Parry concerning tradition's inherent collectivity, but also (particularly in light of his view of the artist recreating the tradition) from a specific conception as to how tradition operates, which stresses, in the most 
general terms, fluidity over rigidity. It has moreover become increasingly common (under the influence, perhaps, of contemporary theories of intertextuality) to see the oral tradition as, rather than a "long chain of interlocking conversations between members of the group" (Goody \& Watt, 1968:29), something inherently multifaceted, multidirectional rather than simply linear. Foley (1992:276) expresses this well:

I have assumed tradition to be a dynamic, multivalent body of meaning that preserves much that a group has invented and transmitted but that also includes as necessary defining features both an inherent indeterminacy and a predisposition to various kinds of changes or modifications. I assume, in short, a living and vital entity with synchronic and diachronic aspects that, over time and space, will experience (and partially constitute) a unified variety of receptions.

It is a fair argument that oral tradition presented in this way makes nonsense of the idea of the oral text "shackled by convention", an idea mostly advanced by detractors of the Parry-Lord thesis (like Vail and White), but also by its followers, at least to the extent that the followers choose to insist on the "formulaic" part of the theory. Had Ong been less under the impression of the formula, Homer might yet have escaped being an assembly-line worker with a phrasebook in his head. Motivated by a similarly flexible view of tradition, Hammond (1987:11) tells us that the "success and quality of a singer's creation [and we have seen how highly he thinks of Homer] will depend on the richness of the tradition within which he works". (Hammond then proceeds to set off the richness of Homer's tradition against - interestingly - the "impoverished tradition" of the guslari, "much studied in recent years for the light they might shed on the Greek tradition, though the illumination is generally oblique and remote".)

For all this talk of a "creative" tradition however, the fact remains, as I have argued elsewhere (Alant, 1996), that the notion of the traditional has never been properly integrated into contemporary literary theory. "Traditional" remains by and large at a counterpoint to the "literary" that the critic sees as his field of endeavour. (It is also, of course, the most obvious counterpoint to the [post-]"modern"). If, as I argued earlier, research into oral tradition has failed to develop a horizon of expectations with regard to the oral text, it is precisely because researchers have been unable to conceive of the text beyond "its" tradition. There is a further point to be made here. We need to remain sensitive to the fact that the notion of tradition is in any event an "organising principle" of a field of knowledge. No matter how wellgrounded it may appear in terms of observed reality, the concept of 
tradition remains, as Michel Foucault (1976:31) has argued, an intellectual tool designed to serve particular interests (those of the researcher). Yai's pessimistic observation (quoted earlier) regarding the lack of communication between the production/reception of the oral text on the one hand and its criticism on the other can be understood in this perspective (Yai, 1989:59). "Tradition" may well be a tool, but it is especially a barrier.

\subsubsection{Creativity as a quality of the receiver/audience}

We have more or less set aside the categories of artist and tradition as instances of orality within which to situate the notion of creativity. I shall not here say anything about genre - it relates more directly to the question of prestige or influence dealt with earlier. We have also talked about the text, and have seen it take on a particularly privileged position. The process of creation (the poietic) "collapses" into the text (Nattiez's "trace" level). But we cannot define the text thus isolated as the "location" of creativity, without committing ourselves to the kind of essentialist definition of literature criticized by Jauss, or without falling into the kind of formalism which has been the basis of the most general criticism of the Parry-Lord thesis. What we can do, however, is to consider what any text received by an addressee (an audience) implies, namely a horizon of expectations. This brings us to Nattiez's esthesic function (the construction of meaning on the part of a receiver), placing us firmly within an aesthetics of reception.

It can be easily forgotten, considering the pains both Parry and Lord took in order to define the artistry of the oral Homer (to convince their readers that the oral-traditional mode of production, irrespective of how different it is to the literate, can indeed be literary), that Parry did not discover the Homeric texts to be oral and then proclaimed them literature. No, the Iliad and the Odyssey had already been lauded as literature - great literature - by successions of generations right up to the modern. Of course, we now know that at least part of this literary appreciation was founded on the kind of "chauvinism" (in Ong's words) Parry managed to "undercut", and we may even agree with the irony in the view expressed by Pierre Macherey, namely that the Iliad appears so different to us compared to what it must have been like for its contemporary public that "it was as if we ourselves had written it" (Macherey, 1977:45). This raises the obvious possibility of Homer being "misread". One conception of the role of the reader mentioned by Jauss (attributed to R.G. Collingwood) claims that a text is only understood "if one has understood the question to which it is an answer" (Jauss, 1982:29). One might rightfully ask: what if the reader finds a different question? Jauss mentions Gadamer's concept of the "fusion of horizons" - the awareness of a work's 
"successive unfolding of the potential for meaning" - as a way of limiting a more or less arbitrary reading. At the same time he concedes, following Gadamer, that the reconstructed question need not stand within the text's original horizon of expectation; "the historical question cannot exist for itself" (Jauss, 1982:30).

There exists an enormous historical and cultural gulf between Homer and his reader, yet the fact remains that even contemporary readers have been able - and Jauss recognises their freedom in this respect - to somehow negotiate the aesthetic distance that is part of that separation, to forge a horizon of expectations in the light of the Homeric text. We also have to concede the following point. It is not impossible that Homer's orality has at times been overemphasised as the "standard" by which his poetry should be interpreted. Hammond invites the prospective reader of Homer to "understand something of the tradition within which the poet worked, and the techniques of composition which that tradition had evolved", but he concludes:

Awareness of the poem's oral composition may rightly affect some points of detailed interpretation: but generally the lliad deserves, and will repay, the approach that would be natural to any great work of literature (Hammond, 1987:14).

We may reflect on exactly what it is that has made orality's most famous text so amenable to horizons of expectations over the ages. Hammond (1987:12) refers to the "tragic quality" underlying the contrast between the traditional poetic style on the one hand, "expressive of an ordered and stable world in which all things have their own excellence and beauty", and the narrative line of pain, destruction and defeat on the other. But this tells us, I would argue, less about the actual text, than it tells us about the possibility of the reader to respond on the basis of the text. This notion of response is crucial, for not all texts that become integrated into a horizon of expectation necessarily elicit response, or at least the same type of response. According to Jauss, the effect (influence) of a text is measured by the extent to which "those who come after it" respond to the text, a response he characterises as the desire to "appropriate", "imitate", "outdo" or "refute"7 (Jauss, 1982:22). In other words, the response can be more or less creative.

$7 \quad$ Jauss could in fact quite easily have used these terms in relation to the reception of oral texts.Yai (1989:63-65) describes the critical practices in the Gèlèdé society of Western Yorubaland which allow, amongst others, for a special kind of "dialogic mode" between performer and audience, as well as "poetic contests". 
Our search for a location of creativity among the different organising principles of orality can therefore bring us to the following. Whether an oral text is literature is determined by its reader/audience or, more precisely, by the latter's response on the basis of his expectation of the text. In terms of the aesthetic distance between the text and the reader's own experience, what kind of a response is the reader/audience inclined to make? It is only at this point that the notion of creativity becomes at all relevant. How creative is the reader/audience's response going to be? The oral text is literature if it allows for a relatively creative response, a response that is not perceived by the reader/audience as, in a sense, pre-determined by his expectation, a response, in other words, that orientates the reader/audience towards as yet "unknown experience". This brings us back to the title of this article. The determining factor in distinguishing the literary from the non-literary is decidedly not whether or not the composer or poet has a phrase book in his head (or is an assembly-line worker). Ong should not have aimed his witticisms at Homer, but rather at the responses of those who have read (or listened to) him.

\section{Conclusion}

The Iliad and Odyssey are particularly privileged oral texts. While their particular position with regard to a powerful Western cultural heritage is an obvious factor in this privilege, there is also a much more mundane reason. They had been written down long before their centuries-long reception.

The same privilege would apply, though to a lesser degree, to oralderived texts in general, particularly those that were written down a long time ago and have therefore been received as part of a large corpus of written literature (the case, generally, of "literate" societies). It is this factor more than anything else which accounts for the greater prestige enjoyed, within research in oral tradition, by the "dead-language" traditions in comparison to the living oral traditions (Foley, 1988:110). The texts produced in a contemporary oral tradition are invariably received as written (transcribed) texts by the researcher or field-worker. The latter may of course qualify the text thus received as "oral literature" and generally does - by mere analogy with the written literary text. A more in-depth appraisal of the text's possible literariness remains more or less impossible, largely due, as I have attempted to show, to the exclusion of the notion of tradition from contemporary literary theoretical perspectives.

The Iliad and Odyssey may well be ultimately privileged. At the same time, however, they have been instrumental, as the original motivation 
for a particularly powerful theory (in which many have acknowledged the dawn of a new discipline), in spawning an interest in oral texts - an interest that indeed extends way beyond those oral texts that have been "derived" into a written form. In this way the Homeric poems have raised the very real possibility of an oral literature - recognised and received as such - which would be much larger than the convention of written literature would allow for.

I have attempted to consider the importance of the Iliad and Odyssey from a literary, rather than "oral-traditional" point of view. This amounts, in fact, to a reconceptualisation of the origins (within the Parry-Lord framework proposed by Ong and Foley) of the "discipline" of Oral Theory. Ideally this literary conception should provide us with a theoretical standard against which all oral texts could be defined, as literature, in the same terms. But our literary horizons of expectations do not extend far enough. To what extent, then, does this conception of the theoretical origins of Oral Theory constitute an advantage over the oralformulaic theory? The attraction of the oral-formulaic theory lies in the concrete criterion it addresses itself to: stylistic form of expression. In so far as it is able to provide a rigorous definition of the latter (but this is becoming increasingly difficult), hypotheses that are made on the basis of the oral-formulaic theory can be objectively "tested". One can count the formulas, hence "quantifiable formulaic analysis" (Foley, 1992:279).

Beauty lies in the eye of the beholder. No matter how rigorously we may try to demarcate its area of influence within a larger process of production, the quality of the postulated response will always defy measurement. But if we take seriously - as much research from various parts of the world has shown - the almost unfathomable variety of oral texts, this very vagueness may, in a sense, be an asset. We cannot say, as a justification for what we are doing, that all oral texts are artful and literary and therefore at least as worthy of contemplation and study, indeed as prestigious, as the canonical literature of Western society has been held to be. But the image of the ultimately privileged oral text Milman Parry presents us with opens, at least, the possibility that other oral texts, from other, less prestigious oral traditions could, given different circumstances of reception, also be literature.

There is, perhaps, a further advantage to this view, relating to what we may call the theoretical coherence of research done in the field of oral tradition. An exclusive adherence to the oral-formulaic theory as a conceptual basis for Oral Theory would mean that a large part of research into oral tradition may well fall outside the scope of Oral Theory - notably in Africa (see Finnegan, 1977; Foley, 1988). African oral traditions - we may think of Zulu and Xhosa praise poetry - certainly 
produce formulaic texts, but the repetition typically found in the African work song - to quote but one example - certainly owes little to the "metrical conditions" that provide the basis of the Homeric formula (Vail \& White, 1991:28). Yet if we see the Homeric poems as essentially providing a kind of theoretical space for the notion of oral literature, then all research that deals with oral texts can be brought into line with Oral Theory, irrespective of the texts' formal properties or the researcher's (lack of) concern with the latter.

In this sense the Iliad and the Odyssey, texts of received excellence in Western society even though not literate, serve as a kind of master metaphor for all oral texts, whether oral-derived or not. The comparison they invite does not confer certainty. But at least we are left with a potential oral literature, which is a definite theoretical improvement on the common reflex to call oral texts "literature" simply by analogy with the written - because there is such a category of written text. For - to return to Ong at the end of this article - is this analogy not the very chauvinism Parry was supposed to have undercut?

\section{Bibliography}

Alant, J.W. 1996. "Did you say 'oral literature'?” asked Walter Ong. Literator, 17(2):117-130.

Barber, K. 1984. Yoruba Oríkì and Deconstuctive Criticism. Research in African Literatures, 15(4):497-518.

Barber, K. \& De Moraes Farias, P. 1989. Introduction. In: Barber, K. \& De Moraes Farias, P. (eds.) Discourse and Its Disguises: The Interpretation of African Oral Texts. Birmingham, U.K. : University of Birmingham. p.1-10.

Bennett, T. 1990. Outside Literature. London : Routledge.

Easthope, A. 1990. Literary into Cultural Studies. London : Routledge.

Finnegan, R. 1973. Literacy versus Non-literacy: The Great Divide? Some comments on the significance of "literature" in non-literate cultures. In: Finnegan, R. \& Horton, R. (eds.) Modes of Thought. London : Faber \& Faber. p.112-144.

Finnegan, R. 1977. Oral Poetry. Its Nature, Significance And Social Context. Cambridge : Cambridge University Press.

Finnegan, R. 1986. The Relation between Composition and Performance: Three Alternative Modes. In: Tokumaru, Y. \& Yamaguti, O. (eds.) The Oral and the Literate in Music. Tokyo : Academia Music. p. 73-86.

Foley, J. 1986. Introduction. In: Foley, J. (ed.) Oral Tradition in Literature. Columbia : University of Missouri Press. p.1-18.

Foley, J. 1988. The Theory of Oral Composition. History and Methodology. Bloomington : Indiana University Press.

Foley, J. 1990. Traditional Oral Epic. The Odyssey, Beowulf, and the Serbo-Croatian Return Song. Berkeley : University of California Press.

Foley, J. 1992. Word-Power, Performance, and Tradition. Journal of American Folklore, 105:275-301.

Foley, J. 1994. Words in Tradition, Words in Text: A Response [to Kelber 1994]. Semeia, 65:169-80.

Foucault, M. 1976. L'archéologie du savoir. Paris : Gallimard. 
Goody, J. \& Watt, I. 1968. The Consequences of Literacy. In: Goody, J. (ed.) Literacy in Traditional Societies. Cambridge : Cambridge University Press. p. 27-68.

Goody, J. 1977. The Domestication of the Savage Mind. Cambridge : Cambridge University Press.

Hammond, M. 1987. Homer. The Iliad. A New Prose Translation. London : Penguin.

Jauss, J. 1982. Towards an Aesthetic of Reception. Minneapolis : University of Minnesota Press.

Kelber, W. 1994. Jesus and Tradition: Words in Time, Words in Space. Semeia, 65:139-67.

Lord, A. 1960. The Singer of Tales. Cambridge : Harvard University Press.

Macherey, P. 1977. Problems of Reflection. In: Barker, F. (ed.) Literature, Society and the Sociology of Literature: Proceedings of University of Essex conference, 1976. Colchester : University of Essex. p. 41-54.

Nattiez, J. 1990. Towards a Semiology of Music. Oxford : Princeton University Press.

Ong, W. 1982. Orality and Literacy. The Technologizing of the Word. New York : Methuen.

Ong, W. 1987. Orality-Literacy Studies and the Unity of the Human Race. Oral Tradition, 2(1):371-382.

Parry, M. 1971. The Making of Homeric Verse. The Collected Papers of Milman Parry. Oxford : Clarendon Press.

Selden, R. 1985. A Reader's Guide to Contemporary Literary Theory. Brighton : Harvester Press.

Vail, L. \& White, L. 1991. Power and the Praise Poem. Charlottesville : University Press of Virginia.

White, L. 1989. Poetic Licence: Oral Poetry and History. In: Barber, K. \& De Moraes Farias, P. (eds.) Discourse and Its Disguises: The Interpretation of African Oral Texts. Birmingham, U.K. : University of Birmingham. p. 34-38.

Yai, O. 1989. Issues in Oral Poetry: Criticism, Teaching and Translation. In: Barber, K. \& De Moraes Farias, P. (eds.) Discourse and Its Disguises: The Interpretation of African Oral Texts. Birmingham, U.K. : University of Birmingham. p. 59-69.

\section{Key concepts:}

aesthetics of oral tradition

oral textuality

reception of Homeric poetry

theory of oral tradition

\section{Kernbegrippe:}

estetika van mondelinge oorlewering (orale tradisie)

mondelinge (orale) tekstualiteit

resepsie van Homeriese epiese gedigte

teorie van mondelinge oorlewering (orale tradisie) 